\title{
Persistence of microbial communities including Pseudomonas aeruginosa in a hospital environment: a potential health hazard
}

\author{
Pedro Miguel de Abreu', Pedro Geadas Farias', Gabriel Silva Paiva², Ana Maria Almeida'
} and Paula Vasconcelos Morais $2,3^{*}$

\begin{abstract}
Background: The persistence of microbial communities and how they change in indoor environments is of immense interest to public health. Moreover, hospital acquired infections are significant contributors to morbidity and mortality. Evidence suggests that, in hospital environments agent transfer between surfaces causes healthcare associated infections in humans, and that surfaces are an important transmission route and may act as a reservoir for some of the pathogens.

This study aimed to evaluate the diversity of microorganisms that persist on noncritical equipment and surfaces in a main hospital in Portugal, and are able to grow in selective media for Pseudomonas, and relate them with the presence of Pseudomonas aeruginosa.
\end{abstract}

Results: During 2 years, a total of 290 environmental samples were analyzed, in 3 different wards. The percentage of equipment in each ward that showed low contamination level varied between $22 \%$ and $38 \%$, and more than $50 \%$ of the equipment sampled was highly contaminated. P. aeruginosa was repeatedly isolated from sinks (10 times), from the taps' biofilm (16 times), and from the showers and bedside tables (two times). Two ERIC clones were isolated more than once. The contamination level of the different taps analyzed showed correlation with the contamination level of the hand gels support, soaps and sinks. Ten different bacteria genera were frequently isolated in the selective media for Pseudomonas. Organisms usually associated with nosocomial infections as Stenotrophomonas maltophilia, Enterococcus feacalis, Serratia nematodiphila were also repeatedly isolated on the same equipment.

Conclusions: The environment may act as a reservoir for at least some of the pathogens implicated in nosocomial infections. The bacterial contamination level was related to the presence of humidity on the surfaces, and tap water (biofilm) was a point of dispersion of bacterial species, including potentially pathogenic organisms. The materials of the equipment sampled could not be related to the microbial contamination level. The presence of a disinfectant in the isolation medium suggests that the number of microorganism in the environment could be higher and shows the diversity of disinfectant resistant species. The statistical analysis suggests that the presence of bacteria could increase the risk of transmission by hand manipulation.

Keywords: Pseudomonas aeruginosa, Hospital environment, Surface microbial colonization, Stenotrophomonas maltophilia

\footnotetext{
* Correspondence: pvmorais@ci.uc.pt

${ }^{2}$ IMAR - Marine and Environmental Research Centre, University of Coimbra,

3004-517 Coimbra, Portugal

${ }^{3}$ Department of Life Sciences, FCTUC, University of Coimbra, 3004-517

Coimbra, Portugal

Full list of author information is available at the end of the article
}

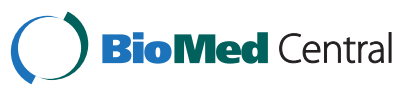

(C) 2014 de Abreu et al.; licensee BioMed Central Ltd. This is an Open Access article distributed under the terms of the Creative Commons Attribution License (http://creativecommons.org/licenses/by/2.0), which permits unrestricted use, distribution, and reproduction in any medium, provided the original work is properly credited. The Creative Commons Public Domain Dedication waiver (http://creativecommons.org/publicdomain/zero/1.0/) applies to the data made available in this article, unless otherwise stated. 


\section{Background}

Hospitals are environments where both, infected and non-infected people, group. How microbial communities persist and change in indoor environments is of immense interest to public health. Recent work showed that humans alter the microbiome in a space when they occupy that space [1]. Building materials and equipment seem also to influence the community composition. For instance, recent studies show that materials made of copper have lower surface burden than stainless steel or plastic materials $[2,3]$.

The potential for contracting a microbial pathogen is highest within a hospital environment [4]. Hospital acquired infections (HAI) are significant contributors to morbidity and mortality, with no values attributed (in http://www.who.int/en/), the Center for Disease Control defined the baselines for HAI as those occurring more than $48 \mathrm{~h} / 72 \mathrm{~h}$ after healthcare admission and within 10 days after hospital discharge [5]. Despite the lack of direct evidence to prove that environmental contaminants are responsible for HAIs, there is an increasing evidence suggesting that the environment may act as a reservoir for at least some of the pathogens causing HAIs [6-9]. Therefore, by touching contaminated surfaces and noncritical equipment, hands may acquire and transfer microorganisms to other inanimate objects or to patients $[10,11]$. Guidelines on treatment of surfaces in hospitals take into account parameters which are considered to be relevant for preventing the transmission of nosocomial pathogens, such as the type of ward or the expected frequency of hand contact with a surface [12].

The presence of susceptible patients in hospital makes more important the adverse impact of the environment on the incidence of health-care-associated infections. Data from the World Health Organization show that nowadays in every 100 hospitalized patients 7 to 10 are expected to contract, at least, one health care-associated infection [13]. Hospital-associated pathogens are commonly found on physician's and nursing staff's clothing [14,15], cell phones [16,17], stethoscopes [18], computer keyboards [19], telemetry leads [20], electronic thermometers [21], blood-pressure cuffs [22], and gels for ultrasound probes [23]. The outbreaks of Pseudomonas aeruginosa [24] linked to water and aqueous solutions used in health-care facilities are examples of these health-care-associated infections. Additionally, clinically important opportunistic organisms linked to water are Pseudomonas spp., Acinetobacter baumannii Burkholderia cepacia, Ralstonia pickettii, Stenotrophomonas maltophilia, and Sphingomonas spp. Modes of transmission for waterborne infections include direct contact, ingestion of water, indirect-contact, inhalation of aerosols dispersed from water sources and aspiration of contaminated water [12].

In this work, we hypothesizes that the existing microbial communities, associated with the surfaces and noncritical equipment, do influence the colonization of other organisms as Pseudomonas aeruginosa, one of the major agents for nosocomial infections, and make them available to be transferred. The aim of the present work was to evaluate the diversity of microorganisms able to grow in selective medium for Pseudomonas including $P$. aeruginosa that persists on noncritical equipment and surfaces in a hospital.

\section{Results}

\section{General level of contamination of the equipment in} each ward

The study included 4 of wards, sampled during 9 months, between February 2010 and September 2011. The samples were recovered from $10 \mathrm{~cm}^{2}$ area using a swab soaked in Tryptic Soy Broth. A total of 290 environmental samples were analyzed for bacterial colonization. The samples were plated in Pseudomonas isolation agar medium (PIA) which is a selective medium used for the isolation of P. aeruginosa and other Pseudomonas species [25]. The number of colonies growing on PIA medium varied in the different equipment sampled. However, a pattern could be defined when considering three classes of level of contamination defined from the amount of counts obtained on PIA medium, based on the accuracy of plate counts enumeration [26]. The first level of contamination included equipment with less than $10 \mathrm{CFU}$ per plate (low contaminated), $10 \mathrm{CFU}$ per plate are considered the minimum CFUs for statistical significance, the second included equipment with $\mathrm{CFU}$ between 10 and $200 \mathrm{CFU}$ per plate (medium contaminated), and the equipment with more than $200 \mathrm{CFU}$ per plate were included in the third level (high contaminated), CFU counts over 200 are considered uncountable due to spatial growth restrictions.

The percentage of equipment in each ward that showed low contamination level varied between $22 \%$ and $38 \%$ (Figure 1). Equipment with a surface number of CFU varying between 10 and $200 \mathrm{CFU}$ were a minority in all wards (maximum 15\%) and, in all wards, more than $50 \%$ of the equipment sampled had more than 200 CFU per sample. The level of colonization of the equipment was similar in the UCI compared to the Medicine I and II and Urology wards.

The majority of the samples collected in taps and sinks showed high level of contamination (Table 1). This pattern of contamination was observed during the 2 years of sampling. High level of contamination was also detected in the showers but in a low number of samples. On the other hand, contamination on surface countertops and trays was detected only in spring samples (March 2010 and April 2011). The noncritical equipment manipulated mostly by the medical personnel as workbenches, stethoscopes and other medical equipment was either not contaminated or 


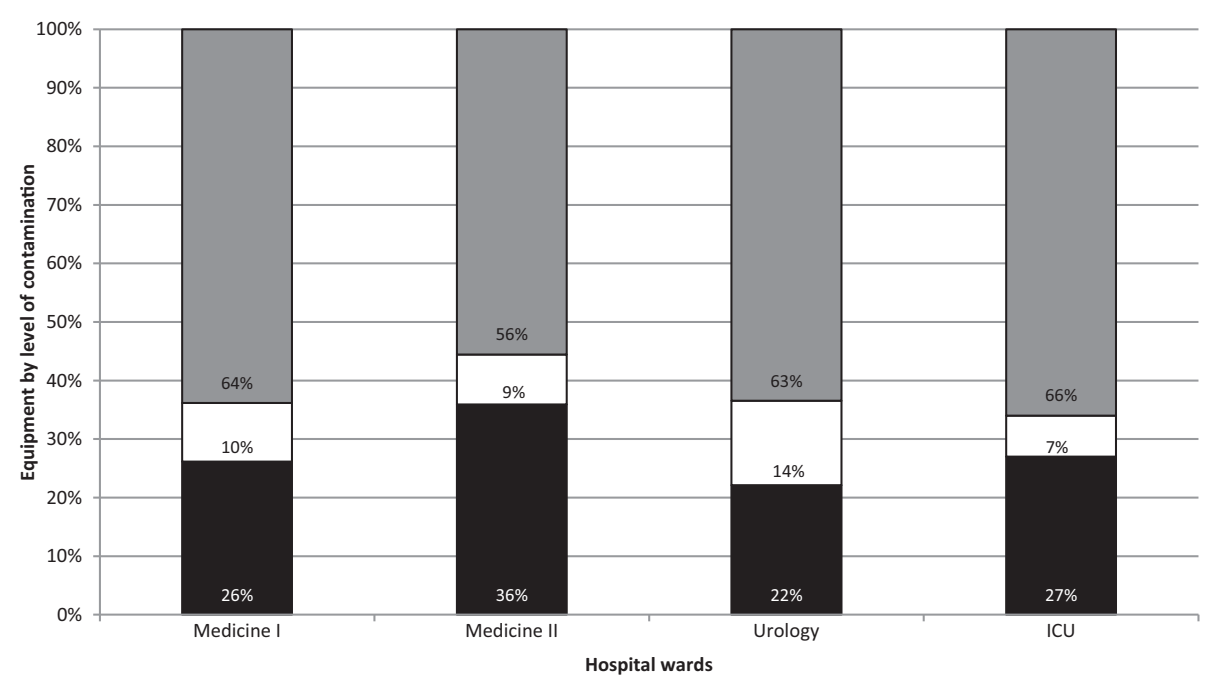

Figure 1 Percentage of equipment with different levels of contamination. Low level contamination (blue), medium level of contamination (red) and high level of contamination (green).

low contaminated (six samples in 2 years), but when the oxygen flask was found contaminated (one sample), the contamination level was high.

The contamination level of the different taps analyzed showed a correlation of 0.9 and 0.8 with the contamination level of the hand gels support and with the soaps and sinks, respectively $(\mathrm{p}<0.05)$. The correlation of tap contamination was only of 0.6 with the samples collected in the showers $(\mathrm{p}<0.05)$. On the other hand, tap contamination level correlated in less than $0.2(\mathrm{p}<0.01)$ with the contamination of the workbenches and the trays of the clinical personnel, and with the contamination of the bed and bedside table.

The equipment that showed persistently a high level of contamination were the surface of sinks, the taps, the hand gels and soaps and the showers. The number of highly contaminated samples from these equipment increased in samples collected during summer and fall, in both years, except for the samples collected on hand gels. The number of positive samples on hand gel/soap was high but only during a short period (until the end of 2010) (Figure 2).

Table 1 Percentage of microbial colonization obtained in the different equipment during the two years sampling

\begin{tabular}{|c|c|c|c|c|c|c|c|c|c|c|c|c|c|c|c|c|c|c|}
\hline \multirow[t]{2}{*}{ Colony Count } & \multicolumn{2}{|c|}{ Feb 2010} & \multicolumn{2}{|c|}{ Apr 2010} & \multicolumn{2}{|c|}{ Jun 2010} & \multicolumn{2}{|c|}{ Oct 2010} & \multicolumn{2}{|c|}{ Dec 2010} & \multicolumn{2}{|c|}{ Feb 2011} & \multicolumn{2}{|c|}{ Mar 2011} & \multicolumn{2}{|c|}{ Jun 2011} & \multicolumn{2}{|c|}{ Sep 2011} \\
\hline & Low & High & Low & High & Low & High & Low & High & Low & High & Low & High & Low & High & Low & High & Low & High \\
\hline ink (p & 15.4 & 47.6 & 15.8 & 46.2 & 27.3 & 34.3 & - & 34.2 & 23.1 & 30.0 & 25.0 & 54.2 & 12.5 & 58.8 & 12.5 & 62.2 & 28.6 & 52 \\
\hline Tap & 7.7 & 4.8 & - & 23.1 & 36.4 & 34.3 & 25.0 & 31.6 & 38.5 & 45.0 & 31.3 & 37.5 & 50.0 & 26.5 & $5-$ & 29.7 & 42.9 & 29 \\
\hline Countertop (sinks) & - & - & 15.8 & 15.4 & - & - & - & 2.6 & - & - & - & - & 12.5 & 2.9 & - & - & - & \\
\hline Workbench & 15.4 & 4.8 & 15.8 & 7.7 & - & - & - & 10.5 & 7.7 & 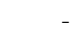 & - & 4.2 & 12.5 & 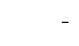 & 12.5 & 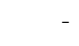 & 7.1 & \\
\hline Shower (+handrail) & 7.7 & 14.3 & - & - & - & 8.6 & - & 13.2 & . & 5.0 & 6.3 & 4.2 & - & 5.9 & - & 5.4 & - & \\
\hline edside table & 15.4 & 4.8 & 10.5 & 7.7 & 27.3 & 5.7 & 12.5 & 2.6 & 7.7 & - & 12.5 & - & - & 2.9 & 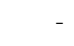 & - & 14.3 & \\
\hline Handrail bed (+bed) & - & 4.8 & 5.3 & - & - & - & - & 2.6 & - & - & - & - & - & - & - & - & - & \\
\hline Serum support & - & - & 10.5 & - & - & - & - & - & - & - & - & - & 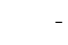 & 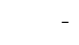 & - & - & - & \\
\hline Oxygen flask & - & 4.8 & - & - & - & - & - & - & 7.7 & - & - & - & - & - & - & - & - & \\
\hline Stethoscope & 7.7 & - & - & - & - & - & 12.5 & - & - & - & - & - & - & 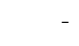 & - & - & - & \\
\hline Equip bedside & - & - & - & - & - & - & - & - & - & - & - & - & - & - & - & - & - & \\
\hline Medical equipments & 7.7 & 9.5 & 15.8 & - & - & - & 12.5 & - & 7.7 & - & - & - & - & 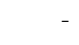 & - & - & - & 2 \\
\hline Tray & 23.1 & 4.8 & 5.3 & - & 9.1 & 5.7 & 12.5 & - & 7.7 & 5.0 & 12.5 & - & - & - & - & 2.7 & - & \\
\hline Hand gel/soap & - & - & - & - & - & 11.4 & 25.0 & 2.6 & - & 15.0 & 12.5 & - & - & - & 25.0 & - & 7.1 & \\
\hline Table (meal/work) & - & - & 5.3 & - & - & - & - & - & - & 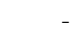 & - & - & 12.5 & 2.9 & - & - & - & \\
\hline
\end{tabular}




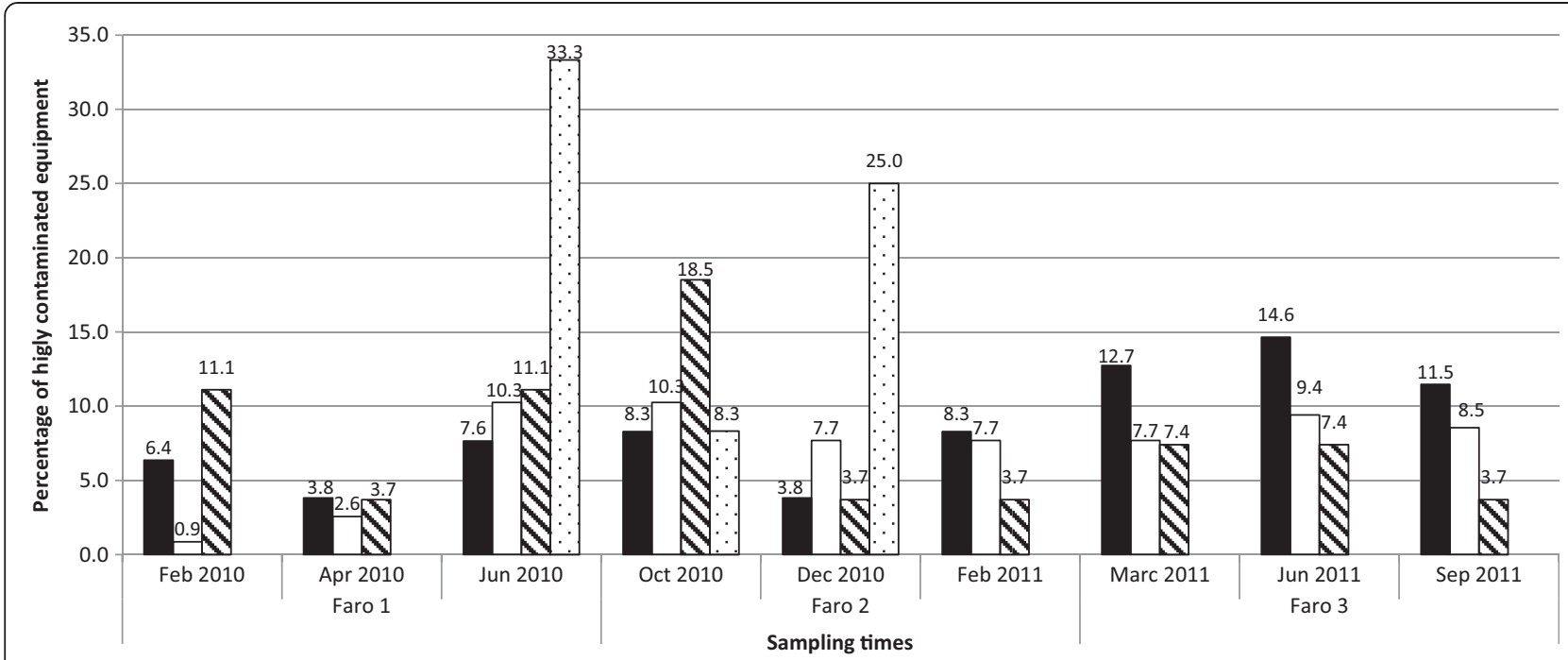

Figure 2 Variation of the number of highly contaminated equipment; porcelain sink ( $\square$ ), tap $(\square)$, shower and handrail ( $\mathbf{D}$ ), hand gel/soap ( $\because$ ); during the sampling period per group of equipment selected based on the persistence and level of contamination.

\section{Diversity of isolates recovered on the equipment and identified by $16 \mathrm{~S}$ rRNA gene sequence}

PIA medium recovered strains of $P$. aeruginosa but also strains belonging to 10 different bacterial genera, although its formulation was conceived to be a selective medium for Pseudomonas. The medium was able to isolate bacteria belonging to the family Pseudomonas as well as gram positive bacteria as Bacillus aryabhattai and Neisseria subflava.

Strains of $P$. aeruginosa were isolated in all equipment showing a high number of samples with high level of contamination (Table 2). P. aeruginosa was repeatedly isolated in the sinks (10 times), in the biofilm of the taps (16 times), in the showers and bedside tables (two times). The analysis of REP profiles suggest the existence of 2 clones. Clone A included 2 strains from sampling time F4 (F4-42 and F4-44), isolated from a sink and a tap, and from sampling time F3 (F3-6) also from a tap but from a different ward. Clone B included two strains (F4-6b and F7-6a) from different sampling times (F4 and F7) isolated from the same tap (Additional file 1: Figure S1).

The isolation of strains from the species $P$. aeruginosa was expected since the isolation conditions favoured its recovery. However, Stenotrophomonas maltophilia, Enterococcus feacalis, Sphingobium yanoikuyae and Serratia nematodiphila were also repeatedly isolated on the same equipment, on different times. Seven different species of Pseudomonas were isolated on the sinks surfaces. Some of these species were also isolated on other surfaces as $P$. beteli on hand gel/soap, workbench and bedside table. P. montelli was also isolated on the sink surfaces, taps, showers and bedside tables.
Some of the organisms isolated were already reported as pathogenic. This is the case of Citrobacter braakii, $C$. freundii, E. faecalis, P. mosselii, P. putida, S. maltophilia, Neisseria subflava, P. alcaligenes or isolated from hospital environment as $P$. monteilii.

The principal component analysis was carried to correlate the level of contamination of the equipment with the bacterial diversity present during the sampling period. The cumulative percentage variance of species was 50.2. The PCA analysis grouped the samples in two major groups: moistened samples (A), with a sub-group of samples directly contacting with tap water (B) and samples manipulated mostly by the hospital personnel (C) (Figure 3); table for meal and work, handrail and bedside (equipment) were not grouped.

\section{Discussion}

Microorganisms are ubiquitous in our environment, including indoor air, and do not necessarily constitute a health hazard. Depending on the individual, the concentration at which contamination becomes a threat to health is unknown [9]. Inanimate surfaces and noncritical equipment have often been described as the source for outbreaks of nosocomial infections [27-29]. The aim of this work was to evaluate, in a Portuguese hospital facility, the number and diversity of microorganisms that persist on inanimate surfaces and noncritical equipment, able to grow on the selective media for $P$. aeruginos $a$ and relate them with the presence of the opportunistic pathogen $P$. aeruginosa.

Data is available on the microbial composition of dust from different environments, showing Gram-positive as dominants, with the most abundant phylum being Firmicutes [7]. However, other studies on the microbial 
Table 2 Diversity of bacteria isolated and identified by 16S rRNA gene sequencing

\begin{tabular}{|c|c|c|c|c|c|c|c|c|c|c|}
\hline \multirow[b]{2}{*}{ Month/Year } & \multicolumn{9}{|c|}{ Samples showing fluorescence by month and year } & \multirow{2}{*}{$\begin{array}{l}\text { Organisms isolated } \\
\text { (number of strains) }\end{array}$} \\
\hline & F 10 & A 10 & $\mathrm{~J} 10$ & 010 & D 10 & F 11 & M 11 & $\mathrm{~J} 11$ & S 11 & \\
\hline \multirow[t]{17}{*}{ Sink } & 3 & 6 & 4 & 4 & 7 & 16 & 8 & 9 & 10 & Acinetobacter pittii \\
\hline & & & & & & & & & & Bacillus aryabhattai \\
\hline & & & & & & & & & & Citrobacter braakii \\
\hline & & & & & & & & & & Citrobacter freundii \\
\hline & & & & & & & & & & Enterococcus faecalis \\
\hline & & & & & & & & & & Pseudomonas aeruginosa (10) \\
\hline & & & & & & & & & & Pseudomonas beteli* \\
\hline & & & & & & & & & & Pseudomonas hibiscicola \\
\hline & & & & & & & & & & Pseudomonas monteilii \\
\hline & & & & & & & & & & Pseudomonas mosselii \\
\hline & & & & & & & & & & Pseudomonas plecoglossicida \\
\hline & & & & & & & & & & Pseudomonas putida \\
\hline & & & & & & & & & & Pseudomonas taiwanensis \\
\hline & & & & & & & & & & Serratia nematodiphila \\
\hline & & & & & & & & & & Sphingobium yanoikuyae (2) \\
\hline & & & & & & & & & & Stenotrophomonas maltophilia (3) \\
\hline & & & & & & & & & & Stenotrophomonas rhizophila \\
\hline \multirow[t]{9}{*}{ Tap } & - & 3 & 3 & 5 & 9 & 5 & 8 & 7 & 7 & Citrobacter braakii \\
\hline & & & & & & & & & & Enterococcus faecalis (2) \\
\hline & & & & & & & & & & Erwinia aphidicola \\
\hline & & & & & & & & & & Neisseria subflava \\
\hline & & & & & & & & & & Pseudomonas aeruginosa (16) \\
\hline & & & & & & & & & & Pseudomonas hibiscicola \\
\hline & & & & & & & & & & Pseudomonas monteilii \\
\hline & & & & & & & & & & Serratia nematodiphila (2) \\
\hline & & & & & & & & & & Stenotrophomonas maltophilia (6) \\
\hline \multirow[t]{3}{*}{ Shower (Handrail) } & 1 & 1 & 2 & 1 & 1 & 1 & - & 2 & - & Pseudomonas aeruginosa (2) \\
\hline & & & & & & & & & & Pseudomonas plecoglossicida \\
\hline & & & & & & & & & & Pseudomonas monteilii \\
\hline \multirow[t]{4}{*}{ Hand Gel (soap) } & - & - & 1 & - & 3 & - & - & - & - & Pseudomonas aeruginosa \\
\hline & & & & & & & & & & Pseudomonas beteli* \\
\hline & & & & & & & & & & Shewanella oneidensis \\
\hline & & & & & & & & & & Citrobacter freundii \\
\hline \multirow[t]{2}{*}{ Workbench/ S. countertop } & 1 & 1 & - & 4 & - & - & 1 & - & - & Pseudomonas aeruginosa \\
\hline & & & & & & & & & & Pseudomonas beteli* \\
\hline Tray & - & - & 2 & - & 2 & - & - & - & 2 & Pseudomonas aeruginosa \\
\hline \multirow[t]{3}{*}{ Bedside Table } & 1 & - & 2 & - & 1 & - & - & - & - & Pseudomonas aeruginosa (2) \\
\hline & & & & & & & & & & Pseudomonas beteli* \\
\hline & & & & & & & & & & Pseudomonas monteilii \\
\hline Bedside equipment & - & - & - & - & - & - & - & 1 & - & Pseudomonas aeruginosa \\
\hline \multirow[t]{2}{*}{ Table (work/meal) } & - & 1 & - & - & - & - & 1 & - & 1 & Pseudomonas alcaligenes \\
\hline & & & & & & & & & & Pseudomonas putida \\
\hline
\end{tabular}




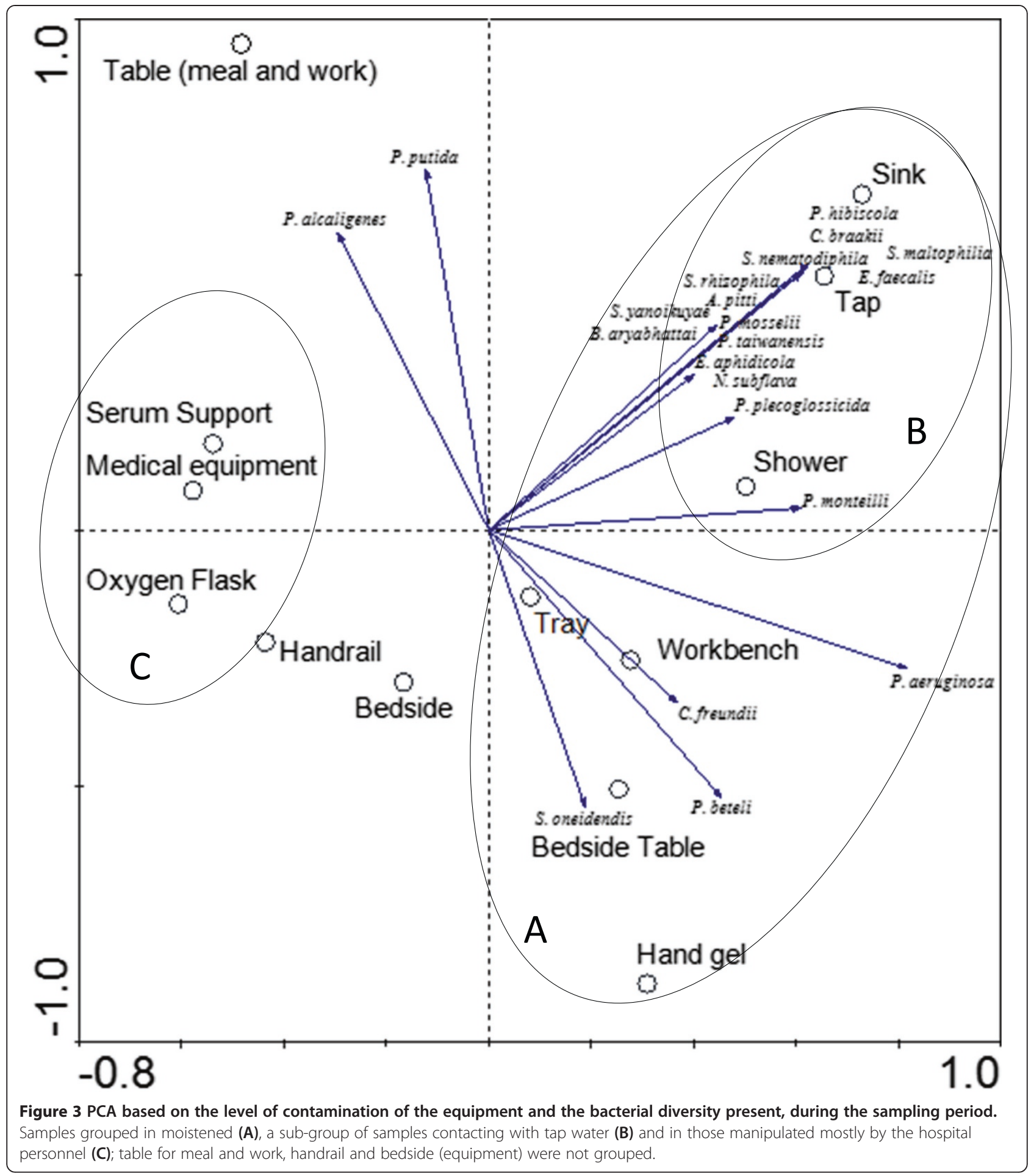

diversity of the environmental surfaces are mainly evaluating the bacterial counts on cloths and other equipment from medical personnel [15].

In the present study, PIA medium was used to recover microorganisms from noncritical equipment and from surfaces, dry or wet. PIA is an isolation medium selective and differential for $P$. aeruginosa, since this species has innate resistance to low Irgasan concentrations [30]. Nevertheless, 10 different bacterial genera of Gram negative and Gram positive bacteria were isolated in the medium which seems to indicate that these organisms are resistant to the biocide and could possibly have multidrug 
efflux systems to extrude the antimicrobial Triclosan (Irgasan) as it occurs in P. aeruginosa [31]. This conclusion is supported by the detection of clonal isolates from different sampling times. The presence of this toxic in many household antibacterial products and antiseptics can probably select for microorganisms able to resist to low concentrations of this biocide [30]. Many Gram-negative species were isolated, which is according to previous reports showing that strains from Acinetobacter spp., Klebsiella spp., Shigella spp., E. coli, P. aeruginosa, or S. marcescens are able to survive for months on surfaces [32]. These species are among the most frequent isolates from patients with nosocomially acquired infections [32]. Moreover, all isolates from this work are resistant to the disinfectant Triclosan, on the other hand, not all the microorganisms present in the environment were isolated.

$P$. aeruginosa is described to persist from 6 hours to 16 months on surfaces and its persistence was related with humidity conditions $[32,33]$. P. aeruginosa was also found in the present work, as part of the microbial community of surfaces with high moister and also in the biofilm of taps. Even though, ubiquitous in the environment, the prevalence of this species in the community is less than in the hospital, and cases of severe community-acquired infection are rare [34]. Pseudomonas have been implicated in different clinical syndromes and diseases transmitted mostly directly by aerosols or indirectly by moist environmental surfaces via hands of health-care workers [12,35]. In the present work, biofilm tap water was the major environmental source of pseudomonads in the healthcare facility. This conclusion is in agreement with previous findings where biofilms, sink and patient room design were involved in the propagation of a $P$. aeruginosa outbreak [35]. Moreover, humidity (wet materials) improved the presence of high numbers of different bacteria species which are clinically important opportunistic organisms as other Pseudomonas as P. mosselii, P. putida, P. alcaligenes, Citrobacter braakii, C. freundii, E. faecalis, S. maltophilia, N. subflava, as found before [36,37].

In the hospital studied S. maltophilia was isolated nine times in the sinks and in the biofilm of the taps, E. faecalis and S. nematodiphila were repeatedly isolated, two times each, in tap water biofilms, and S. marcescens and Enterobacter spp. were also isolated during the present study. The described genera were reported to be responsible for healthcare-associated episodes of colonization, including respiratory and urinary tracks, bloodstream infections and pneumonia [5,12,38]. E. faecalis, S. nematodiphila, S. marcescens and Enterobacter spp. are commonly associated with transmission by hand carriage and hand transfer [39]

The different type of materials tested did not reveal a consistent (high or low) contamination level. Some investigators reported that the type of material has no influence on the persistence of bacteria, other described a longer bacterial persistence on plastic, others on steel, or a shorter survival on copper $[2,3,32,40]$. The statistical analysis of the results based on the contamination level, number of times contaminated and type of material, grouped samples on the base of the group of persons that manipulated the equipment, on the presence or absence of humidity and contact with tap water, but not based on their type of material. This study used a selective medium with a disinfectant to evaluate the microbial colonization of the surfaces and noncritical equipment, revealing the prevalence of a diverse group of microbial species with mechanisms of resistance to the antiseptic, most of them with potential to be involved in nosocomial infections.

\section{Conclusion}

The potential for contracting a microbial pathogen is highest within a hospital environment and hospital acquired infections are significant contributors to morbidity and mortality. Despite the lack of direct evidence to prove that environmental contaminants are responsible for hospital acquired infections, there is an increasing evidence suggesting that the environment may act as a reservoir for at least some of the pathogens causing nosocomial infections. This work showed that many different bacterial species can persist on surfaces for months and years. The level of bacterial contamination was related with the presence of humidity on the surface, and tap water (biofilm) was a point of dispersion of bacterial species, usually involved in nosocomial infections as Pseudomonas aeruginosa, Stenotrophomonas maltophilia and Enterococcus feacalis. Their presence in the environment, as it seems to be pointed by the analysis of the diversity, increases the risk of transmission to the different materials during hand manipulation.

\section{Methods}

\section{Sampling (ICU, Medicine I, Medicine II and Urology)}

The study was carried out at the Hospital de Faro, Portugal, which serves a resident population of about 253 thousand people and this value may double or triple the population seasonally (in http://www.hdfaro.min-saude. pt/site/index.php). Between January 2010 and September, 2011, the hospital was evaluated 12 times (sampled each two months) and four different wards were investigated for environmental contamination of the following surfaces and equipment: sink, tap (biofilm), surface countertop and workbench of the nurses area, shower (and handrail), bedside table, handrail bed (including bed), serum support, oxygen flask, stethoscope, equipment at bedside, other medical equipment, tray used by nurses, hand gel/soap, table (meal and work). The equipment considered in this study is included in the category of noncritical hospital objects and surfaces. These items have been said to pose no 
risk to patients, nevertheless, these surfaces and equipment are frequently touched by hand can contribute to the spread of healthcare-associated pathogens as Pseudomonas aeruginosa, Staphilococus aureus, or Acinetobacter baumanii. The evaluation was performed in wards of the Medical Unit I and II, Urology and Intensive Care Unit.

Samples were collected in the wards, always in the same period of the day, at the end of the morning and during lunch time, after the medical visits and treatments, and also sometime after a ward cleaning. Swabs were used for collecting the organisms present in an area of $10 \times 10 \mathrm{~cm}$ of each surface. Taps were sampled by removing the biofilm. The swabs were first humidified in Tryptic Soy Broth (TSB - Oxoid, Basingstoke, Hampshire, England), then used to sample, and transported in $2 \mathrm{ml}$ of TSB tubes and then processed in the laboratory after $3 \mathrm{~h}$ shaking.

\section{Number of cultivable microorganisms on equipment and bacterial isolation}

Each volume of transporting broth containing single swabs was vortexed for $1 \mathrm{~min}$. A total of 290 environmental samples were analysed for bacterial colonization by inoculating $0.1 \mathrm{ml}$ of the swab suspension in Pseudomonas Isolation Agar (PIA) (Difco). PIA is a selective medium including the antibiotic Irgasan for the isolation of Pseudomonas and differentiating Pseudomonas aeruginosa from other pseudomonads on the basis of pigment formation. Samples were incubated $24 \mathrm{~h}$ at $30^{\circ} \mathrm{C}$, and evaluated after this period for total counts and for the presence of colonies with fluorescence under UV light. All colonies showing fluorescence were isolated and purified. From plates positive for fluorescence, a significant number of nonfluorescent colonies were also isolated.

\section{S rRNA gene sequence identification of the isolates}

DNA from each isolate was obtained using the protocol from Pitcher et al. [41] with the following modifications: an extra washing step with a second volume of 24:1 (v/v) of chloroform/isoamyl-alcohol and an additional centrifugation step for $15 \mathrm{~min}$ at $13200 \mathrm{rpm}$ were added. Amplification of the nearly full-length $16 \mathrm{~S}$ rRNA gene sequence from each DNA was performed by PCR with primers $27 \mathrm{~F}$ (5'-GAG TTT GAT CCT GGC TCA G - 3') and 1525R (5' - AGA AAG GAG GTG ATC CAG CC - 3') [42]. The PCR reaction was performed according to Proença et al. [43]. Briefly, $30 \mu \mathrm{l}$ reaction mix was amplified using PCR with 30 cycles: $1 \mathrm{~min}$ at $94^{\circ} \mathrm{C}, 1 \mathrm{~min}$ at $53^{\circ} \mathrm{C}$, and $1 \mathrm{~min}$ at $72^{\circ} \mathrm{C}$. The 1500-bp PCR products were purified using the JET Quick PCR Purification Spin Kit (Genomed GmbH, Löhne, Germany) according to the manufacturer's instructions.

All sequences were compared with sequences available in the NCBI database using BLAST network services [44].
Sequences were initially aligned with the CLUSTAL X program [45], visually examined, and relocated to allow maximal alignment. The method of Jukes and Cantor [46] was used to calculate evolutionary distances. Phylogenetic dendrograms were than constructed by the neighbour-joining method using the MEGA4 package [47].

\section{REP typing of $P$. aeruginosa strains}

A primary screen of all isolates was performed by Random Amplification of Polymorphic DNA (RAPD) using DNA amplification reactions in a total volume of $30 \mu \mathrm{l}$ according to Santos et al. 2012 [48]. The RAPD patterns were visually analysed.

Clones of $P$. aeruginosa strains were identified by ERIC-PCR. Polymerase chain reaction, both reaction mix and amplification cycle, followed the protocol outlined by Syrmis, et al. 2004 [49]. Samples were loaded on a $1 \%$ agarose gel with TAE and runned at $75 \mathrm{~V}$ for $1 \mathrm{~h}$, at room temperature.

\section{Statistical analysis}

The correlation (Pearsons) between samples, based on the contamination level, was performed by using Microsoft Excel. Principal Component Analysis was used to analyse the relationships between the level of contamination of the equipment, the type of equipment and the sampling time using the software package CANOCO (version 4.5).

\section{Nucleotide sequence accession numbers}

The 16S rRNA gene sequences of the isolates reported in this study (except strain Faro2_34) have been deposited in EMBL database under the accession numbers from KF792126 to KF792306.

\section{Additional file}

\begin{abstract}
Additional file 1: Figure S1. ERIC-PCR profiling of: Pseudomonas
aeruginosa strains f2-3b, faro2 29a, faro3 3a, faro3 6, faro3 10a, faro3 16a, faro 4 6b, faro 4 42, faro4 44, faro 4 47a, faro6 39a, faro $76 a$ and faro 7 10, faro 717 and faro 8 20, figure a) from left to right. On figure b) the strains P. aeruginosa faro 826 , faro 836 a, faro 840 a, faro6 $5 a$, faro6 42 , faro $720 \mathrm{c}$ and faro8 6. Samples loaded on electrophoresis gel $1 \%$ agarose, $70 \mathrm{~V}$, $60 \mathrm{~min}$, stained with ethidium bromide.
\end{abstract}

\section{Competing interests}

The authors declare that they have no competing interests.

\section{Authors' contributions}

PA performed the sample collection and laboratory work including DNA extraction, bacteria identification and antibiotic testing. PF performed the sequence submission to data bank and in the manuscript. GP performed sampling and bacterial isolation. AA contributes in the study design and manuscript revising. PVM conceived of the study, participated in the overall design and coordination and the manuscript. All authors read and approved the final manuscript. 


\section{Acknowledgements}

We acknowledge the Hospital de Faro and its Director for the permission for sampling. This research was partially supported in part by Instituto Piaget, Portugal, through the project 'Estudo da variabilidade genética e da prevalência de Pseudomonas aeruginosa em ambiente hospitalar' and from FCT project PTDC/MAR/109057/2008. PA and PF were supported by Instituto Piaget, Portugal, fellowships. GP was supported by FCT, Portugal, fellowship PTDC/AGR-CFL/115373/2009. We thank Christophe Espírito-Santo, for critical discussion of the manuscript.

\section{Author details}

${ }^{1}$ Instituto Piaget, Enxerim 8300-025, Silves, Portugal. ${ }^{2}$ IMAR - Marine and Environmental Research Centre, University of Coimbra, 3004-517 Coimbra, Portugal. ${ }^{3}$ Department of Life Sciences, FCTUC, University of Coimbra, 3004-517 Coimbra, Portugal.

Received: 16 January 2014 Accepted: 14 April 2014

Published: 8 May 2014

\section{References}

1. Smith D, Alverdy J, An G, Coleman M, Garcia-Houchins S, Green J, Keegan K, Kelley ST, Kirkup BC, Kociolek L, Levin H, Landon E, Olsiewski P, Knight R, Siegel J, Weber S, Gilbert J: The Hospital Microbiome Project: Meeting Report for the 1st Hospital Microbiome Project Workshop on sampling design and building science measurements, Chicago, USA, June 7th-8th 2012. Stand Genomic Sci 2013, 8:112-117.

2. Espírito Santo C, Lam EW, Elowsky CG, Quaranta D, Domaille DW, Chang CJ, Grass G: Bacterial killing by dry metallic copper surfaces. Appl Environ Microbiol 2011, 77:794-802

3. Santo CE, Quaranta D, Grass G: Antimicrobial metallic copper surfaces kill Staphylococcus haemolyticus via membrane damage. Microbiol Open 2012, 1:46-52

4. Adams DA, Gallagher KM, Jajosky RA, Kriseman J, Sharp P, Anderson WJ, Aranas AE, Mayes M, Wodajo MS, Onweh DH, Abellera JP: Summary of Notifiable Diseases - United States, 2011. MMWR Morb Mortal Wkly Rep 2013, 60:1-117.

5. Collins AS: Preventing Health Care - Associated Infections. In Patients Safety and Quality: An Evidence-Based Handbook for Nurses: Vol 2.; 1991:547-576.

6. Casey AL, Adams D, Karpanen TJ, Lambert PA, Cookson BD, Nightingale P, Miruszenko L, Shillam R, Christian P, Elliott TSJ: Role of copper in reducing hospital environment contamination. J Hosp Infect 2010, 74:72-77.

7. Rintala H, Pitkäranta M, Toivola M, Paulin L, Nevalainen A: Diversity and seasonal dynamics of bacterial community in indoor environment. BMC Microbiol 2008, 8:56

8. Gonza M, Heidelberg JF, Whitman WB, Kiene RP, Brinkac L, Lewis M, Johri S, Weaver B, Pai G, Miller TR, Carlton J, Rasko DA, Paulsen IT, Ren Q, Daugherty SC, Deboy RT, Dodson RJ, Sullivan SA, Rosovitz MJ, Haft DH, Selengut J: Genome sequence of Silicibacter pomeroyi reveals adaptations to the marine environment. Nature 2004, 432(December):910-913.

9. Sebastian A, Larsson L: Characterization of the Microbial Community in Indoor Environments: a Chemical-Analytical Approach. Appl Environ Microbiol 2003, 69:3103-3109.

10. Martínez JA, Ruthazer R, Hansjosten K, Barefoot L, Snydman DR: Role of environmental contamination as a risk factor for acquisition of vancomycin-resistant Enterococci in patients treated in a medical intensive care unit. Arch Intern Med 2003, 163:1905-1912.

11. Hayden MK, Blom DW, Lyle EA, Moore CG, Weinstein RA: Risk of hand or glove contamination after contact with patients colonized with vancomycin-resistant Enterococcus or the colonized patients' environment. Infect Control Hosp Epidemiol 2008, 29:149-154.

12. Sehulster L, Chinn R: Guidelines for Environmental Infection Control in Health-Care Facilities. Center for Disease Control (CDC); 2003 [www.cdc.gov/ ncidod/hip/enviro/guide.htm].

13. WHO: Report on the Burden of Endemic Health Care-associated Infection Worldwide; 2011:1-34.

14. Wiener-Well $Y$, Galuty M, Rudensky B, Schlesinger $Y$, Attias $D$, Yinnon AM: Nursing and physician attire as possible source of nosocomial infections. Am J Infect Contro 2011, 39:555-559.

15. Perry C, Marshall R, Jones E: Bacterial contamination of uniforms. J Hosp Infect 2001, 48:238-241.
16. Brady RRW, Verran J, Damani NN, Gibb AP: Review of mobile communication devices as potential reservoirs of nosocomial pathogens. $J$ Hosp Infect 2009, 71:295-300.

17. Datta P, Rani H, Chander J, Gupta V: Bacterial Contamination of Mobile Phones of Health Care Workers. Indian J Med Microbiol 2009, 27:279.

18. Marinella MA, Pierson C, Chenoweth C: The Stethoscope A Potential Source of Nosocomial Infection? Arch Intern Med 2013, 786:790.

19. Doğan M, Feyzioğlu B, Ozdemir M, Baysal B: Investigation of microbial colonization of computer keyboards used inside and outside hospital environments. Mikrobiyol Bul 2008, 42:331-336.

20. Safdar N, Drayton J, Dern J, Warrack S, Duster M, Schmitz M: Telemetry leads harbor nosocomial pathogens. Int J Infect Control 2012, 8:10-12.

21. Livornese LL, Dias S, Samel C, Romanowski B, Taylor S, May P, Pitsakis P, Woods G, Kaye D, Levison ME: Hospital-acquired infection with vancomycin-resistant Enterococcus faecium transmitted by electronic thermometers. Ann Intern Med 1992, 117:112-116.

22. Myers MG: Longitudinal evaluation of neonatal nosocomial infections: association of infection with a blood pressure cuff. Pediatrics 1978, 61:42-45.

23. Schabrun S, Chipchase L, Rickard H: Are therapeutic ultrasound units a potential vector for nosocomial infection? Physiother Res Int 2006, 11:61-71.

24. Trautmann M, Lepper PM, Haller M: Ecology of Pseudomonas aeruginosa in the intensive care unit and the evolving role of water outlets as a reservoir of the organism. Am J Infect Control 2005, 33:S41-S49.

25. Krueger $\mathrm{CL}$, Sheikh W: A new selective medium for isolating Pseudomonas spp. from water. Appl Environ Microbiol 1987, 53:895-897.

26. Sutton S: Accuracy on plate counts. J Validation Tecnhology 2011, 17:42-46.

27. Cisneros JM, Rodriguez-Bano J: Nosocomial bacteremia due to Acinetobacter baumannii: epidemiology, clinical features and treatment. Clin Microbiol Infect 2002, 8:687-693.

28. Weber DJ, Rutala WA, Miller MB, Huslage K, Sickbert-Bennett E: Role of hospital surfaces in the transmission of emerging health care-associated pathogens: norovirus, Clostridium difficile, and Acinetobacter species. Am J Infect Control 2010, 38(5 Suppl 1):S25-S33.

29. Murphy CN, Clegg S: Klebsiella pneumoniae and type 3 fimbriae: nosocomial infection, regulation and biofilm formation. Future Microbiol 2012, 7:991-1002.

30. Chuanchuen R, Beinlich K, Hoang TT, Becher A, Karkhoff-Schweizer RR, Schweizer HP: Cross-resistance between triclosan and antibiotics in Pseudomonas aeruginosa is mediated by multidrug efflux pumps: exposure of a susceptible mutant strain to triclosan selects nfxB mutants overexpressing MexCD-OprJ. Antimicrob Agents Chemother 2001 45:428-432.

31. Chuanchuen R, Karkhoff-Schweizer RR, Schweizer HP: High-level triclosan resistance in Pseudomonas aeruginosa is solely a result of efflux. Am J Infect Control 2003, 31:124-127.

32. Kramer A, Schwebke I, Kampf G: How long do nosocomial pathogens persist on inanimate surfaces? A systematic review. BMC Infect Dis 2006, 6:130.

33. Panagea S, Winstanley C, Walshaw MJ, Ledson MJ, Hart CA: Environmental contamination with an epidemic strain of Pseudomonas aeruginosa in a Liverpool cystic fibrosis centre, and study of its survival on dry surfaces. J Hosp Infect 2005, 59:102-107.

34. Public Health Agency of Canada: Pseudomonas SPP.: Pathogen Safety Data Sheet - Infectious Substances. In Edited by Pathogen Regulation Directorate. ; 2011:1-5.

35. Hota S, Hirji Z, Stockton K, Lemieux C, Dedier H, Wolfaardt G, Gardam MA: Outbreak of multidrug-resistant Pseudomonas aeruginosa colonization and infection secondary to imperfect intensive care unit room design. Infect Control Hosp Epidemiol 2009, 30:25-33.

36. Bert F, Maubec E, Bruneau B, Berry P, Lambert-Zechovsky N: Multi-resistant Pseudomonas aeruginosa outbreak associated with contaminated tap water in a neurosurgery intensive care unit. J Hosp Infect 1998, 39:53-62.

37. Muyldermans G, De Smet F, Pierard D, Steenssens L, Stevens D, Bougatef A, Lauwers S: Neonatal infections with Pseudomonas aeruginosa associated with a water-bath used to thaw fresh frozen plasma. J Hosp Infect 1998, 39:309-314.

38. Khardori N, Elting L, Wong E, Schable B, Bodey GP: Nosocomial infections due to Xanthomonas maltophilia (Pseudomonas maltophilia) in patients with cancer. Rev Infect Dis 1990, 12:997-1003. 
39. Kampf G, Kramer A: Epidemiologic Background of Hand Hygiene and Evaluation of the Most Important Agents for Scrubs and Rubs. Clin Microbiol Rev 2004, 17:863-893.

40. Neely AN: A survey of gram-negative bacteria survival on hospital fabrics and plastics. J Burn Care Rehabi 2000, 21:523-527.

41. Pitcher DG, Saunders NA, Owen RJ: Rapid extraction of bacterial genomic DNA with guanidium thiocyanate. Lett App/ Microbiol 1989, 8:151-156.

42. Rainey FA, Ward-Rainey N, Kroppenstedt RM, Stackebrandt E: The genus Nocardiopsis represents a phylogenetically coherent taxon and a distinct actinomycete lineage: proposal of Nocardiopsaceae fam. nov. Int I Syst Bacteriol 1996, 46:1088-1092.

43. Proença DN, Francisco R, Santos CV, Lopes A, Fonseca L, Abrantes IMO Morais PV: Diversity of bacteria associated with Bursaphelenchus xylophilus and other nematodes isolated from Pinus pinaster trees with pine wilt disease. PLOS ONE 2010, 5:e15191.

44. Altschul SF, Madden TL, Schäffer AA, Zhang J, Zhang Z, Miller W, Lipman DJ: Gapped BLAST and PSI-BLAST: a new generation of protein database search programs. Nucleic Acids Res 1997, 25:3389-3402.

45. Thompson JD, Gibson TJ, Plewniak F, Jeanmougin F, Higgins DG: The CLUSTAL_X windows interface: flexible strategies for multiple sequence alignment aided by quality analysis tools. Nucleic Acids Res 1997 25:4876-4882.

46. Jukes TH, Cantor CR: Evolution of protein molecules. New York: Academic Press; 1990:21-132

47. Tamura K, Dudley J, Nei M, Kumar S: MEGA4: Molecular Evolutionary Genetics Analysis (MEGA) software version 4.0. Mol Biol Evol 2007, 24:1596-1599

48. Santos SS, Pardal S, Proença DN, Lopes RJ, Ramos JA, Mendes L, Morais PV: Diversity of cloacal microbial community in migratory shorebirds that use the Tagus estuary as stopover habitat and their potential to harbor and disperse pathogenic microorganisms. FEMS Microbiol Ecol 2012, 82:63-74.

49. Syrmis MW: Rapid genotyping of Pseudomonas aeruginosa isolates harboured by adult and paediatric patients with cystic fibrosis using repetitive-element-based PCR assays. J Med Microbiol 2004, 53:1089-1096.

doi:10.1186/1471-2180-14-118

Cite this article as: de Abreu et al:: Persistence of microbial communities including Pseudomonas aeruginosa in a hospital environment: a potential health hazard. BMC Microbiology 2014 14:118.

\section{Submit your next manuscript to BioMed Central and take full advantage of:}

- Convenient online submission

- Thorough peer review

- No space constraints or color figure charges

- Immediate publication on acceptance

- Inclusion in PubMed, CAS, Scopus and Google Scholar

- Research which is freely available for redistribution

Submit your manuscript at www.biomedcentral.com/submit
(O) Biomed Central 